\title{
PROFESSIONAL REFLECTION IS A FACTOR OF IMPROVING THE TEACHER'S PROFESSIONALISM
}

\section{Tetiana Scherban}

\section{INTRODUCTION}

At the present stage of society development, high requirements are set to the professionalism of a specialist. A modern specialist is a person who is able to analyze, adjust and improve his/her professional activity. A prerequisite for this improvement is professional reflection.

The rapid changes in society influence the changes of the higher education. After all, the criteria for assessing the effectiveness of specialists have changed. This fact determines the process of systemic reform of the higher education system. In particular, in modern professional psychological models of an ideal specialist, those mental properties that affect the ability to self-development and professional self-improvement acquire more and more importance. In this context, the leading personality trait is reflection. Therefore, an important task of education is to create optimal conditions for the formation and development of professional reflection of future specialists.

As the analysis of the psychological and pedagogical literature shows, the essence of reflection, its mechanisms, processes, methodological, theoretical, experimental and applied problems, have been covered in the researches of S. Yu. Stepanova, M. A. Vislohuzova, N. I. Poviakel, N. O. Postaliuk, Yu. M. Shvalba, T. M. Shcherbakova, and others). Many aspects of reflection have been investigated in the works of many scientists: the place of this phenomenon in the system of professionally significant qualities (E. O. Klimov, M. S. Pryazhnikov, O. F. Bondarenko, L. V. Dolynska, V. H. Panok, N. V. Chepeleva and others); reflection and professional thinking (N. I. Poviakel, M. Yu. Verban, N. V. Prorok, etc.); the role of reflection in axiogenesis (V. M. Mytsko, Z.S. Karpenko, H. K. Radchuk, etc.); reflection in the process of self-actualization of the personal and professional "Self" (Yu. H. Dolinska, L. M. Kobylnik, D. A. Menegetti, etc.); reflection in the formation of professional consciousness (A. A. Alimov; N. O. Kucherovska, N. F. Shevchenko 
and others); reflection and professional identification (T. M. Buiakas, O. O. Minenko, L. B. Schneider, etc.).

The study of professional reflection is an urgent task for all pedagogical specialties. After all, today the school needs a teacher who is able to work independently, creatively and responsibly at a high professional level, to think creatively, to act professionally in problem situations.

The effectiveness of pedagogical activity depends crucially on the level of development of pedagogical reflection. Pedagogical reflection is not just about knowing or understanding the subject itself, it is also about finding out how others know and understand the "reflector", his or her personal characteristics, emotional reactions, and cognitive ideas.

It is believed that the level of reflexive self-regulation of the teacher influences his/her professional skill and is the psychological basis of his/her pedagogical creativity (I. P. Rachenko ${ }^{1}$, M. V. Klarin ${ }^{2}$, Yu. M. Kulutkin, N. O. Postaliuk, etc.). After all, as a form of cognition, reflection is inherent not only critical but also a heuristic principle: it acts as a source of new knowledge. Being aware of the unconscious, cognizing the unknown, reflection considers knowledge about it to be its subject.

E. F. Zeier ${ }^{3}$, E. O. Klimov ${ }^{4}$, A. K. Markova have repeatedly emphasized that professional reflection promotes creative search and improvement of professionalism.

The importance of professional reflection for the process of professionalization is also emphasized in a competent approach. The concept of "reflexive competence" is proposed by O. A. Polishchuk. According to the scientist, reflexive competence is a professional quality of a person, which allows the most efficient and adequate implementation of reflexive processes, the implementation of reflexive

1 Rachenko Y.P. (1999) Psychology of pedagogical creativity. Pyatigorsk: Publishing house of PSLU.

${ }^{2}$ Klaryn M. V. (1994) Innovative models of teaching in foreign pedagogical searches. Moscow.

${ }^{3}$ Zeer E. F. (2003) Psychology of vocational education. Moscow: Publishing House of the Moscow Psychological and Social Institute.

${ }^{4}$ Klymov E. A. (1996) Psychology of professional self-determination. Rostovon-Don: Phoenix. 
ability, which ensures the process of development and selfdevelopment ${ }^{5}$. The criterion of effective pedagogical activity is the ability of the teacher to solve pedagogical and educational tasks. Reflection in this process is the basis of success.

A number of researchers pay attention to the role of reflection in cognition, awareness and self-esteem of professionally significant qualities (V. D. Bragina, V. M. Koziev, V. P. Savrasov, L. O. Hryhorovych, etc.). It is believed that the most important condition for the development of the professionalism of the teacher, an important factor in the effectiveness of his/her pedagogical activity is the teacher's readiness (willingness) to constant "feedback", his/her ability to interpret the information obtained from the school cild's position, to evaluate the effectiveness and appropriateness of the pedagogical decisions that he/she makes, the correctness of approaches to problem situations, etc. ${ }^{6}$. That is, reflection shapes the teacher's perceptual skills.

Despite versatile and thorough research in the theoretical and empirical fields of studying pedagogical reflection, the role of reflection in shaping the ability to solve pedagogical tasks and the development of perceptual skills remains poorly studied. All of the above defines the purpose of the study - to study theoretically and empirically the psychological features of pedagogical reflection in the processes of problem solving and the development of perceptual skills. The object of study is pedagogical reflection. The subject of the study - psychological features of pedagogical reflection in the process of solving problems and developing perceptual skills. According to this purpose, the main tasks of the study have been determined: to study the psychological features of teacher's reflection in the process of solving pedagogical tasks; to study the psychological features of the teacher's reflection in the development of his/her perceptual skills.

${ }^{5}$ Stepanov S. Yu., Polyshchuk O. A. \& Semenov Y. N. (1996) The development of reflective competence of management personnel. Moscow: Progress.

6 Tkachuk S. I. (2010) Psychological and pedagogical bases of professional readiness of future teachers of labor training to formation of technological culture of students in general educational establishments. Scientific journal of MP Dragomanov National Pedagogical University. Series 13: Challenges for Employment and Training, vol. 6. pp. 200-207. 


\section{Psychological features of teacher's reflection in the process of solving pedagogical tasks}

The teacher is not allowed to perform his/her activities in a nonprofessional manner, since the object of his/her influence is the schoolchildren. It is a typical idea that in order to be a good teacher it is necessary to have a thorough knowledge of the subject and have practical experience. The fact is that these are only necessary but not sufficient conditions for the formation of the professionalism of the teacher. Only the constant awareness, analysis and systematization of experience enable the teacher to develop as a professional. The reflexive attitude of the teacher to his/her own activity is an important factor in his/her thorough awareness, critical analysis, and constructive improvement. Thus, reflection enables the individual to go beyond the immediate process, beyond the routine, to take a stand outside it for analysis and drawing conclusions.

In pedagogical activity, the reflexive processes are implemented primarily in the process of:

- interaction of a teacher with a schoolchild. The criterion is the teacher's understanding of the schoolchildren's actions, feelings, and thought processes;

- designing schoolchildren's activities. The criterion is the teacher's development of learning and upbringing goals, constructive ways of achieving them, taking into account the abilities and psychological characteristics of schoolchildren;

- introspection and self-esteem. The criterion is the assessment of one's own activity and oneself as its subject of pedagogical activity.

Pedagogical reflexive actions are manifested in the following:

- in the desire of the teacher to understand the internal mechanisms of the learning process, find out why some teaching methods are effective, while others do not contribute to the promotion of the child, identify some general patterns that govern the learning process, etc., that is, in an effort to get to the bottom of all the phenomena that did not seem to him/her problematic before;

- in the productive nature of the teacher's analysis of his/her practical experience, allows him/her to be "estranged", accessible only for further understanding in the context of the experience of science and its transfer to other people; 
- in the constructive orientation of the reflexive analysis of one's own activity, which allows the teacher to distinguish individual independent tasks from the general structure, the solution of which requires own special methods and approaches. Yes, the learning process can be considered as a process of sequential execution of analytical tasks, that allows the teacher to more differentially approach the search of means for their realization ${ }^{7}$.

The role of reflection in the process of analyzing the teacher's own constructive and methodical schemes, which he/she uses in the process of solving educational problems, is important. The existence of a direct relationship between the teacher's orientation to independence in the design of educational solutions, the level of formation of his/her professional reflection and the methods of selecting information from various sources has been proved. Moreover, it is the reflexive attitude of beginners to themselves as subjects of professional activity that is the basis for the development of pedagogical reflection in them as a necessary condition for professionalism.

The criterion for the professional development of teachers is the ability to successfully solve educational and pedagogical problems ${ }^{8,9,10}$. Such skills can not be developed without an active reflective attitude of the individual. Thus, reflection is the key to forming the ability to solve learning problems.

Educational activity is a continuous series of tasks. Teachers need to be taught how to solve them. The ability to solve educational and pedagogical tasks is also an important criterion for the quality of the acquired knowledge and practical skills, a criterion for qualitative training of future specialists at higher educational institutions. Successful learning process to solve educational and pedagogical problems can be subject to the reflective position of the teacher's personality.

${ }^{7}$ Halkyna N. V. (1990) The psychological mechanism for solving problems of assessment and self-esteem. Psychology of creativity. pp. 149-158.

${ }^{8}$ Kulyutkyna Yu. N. \& Sukhobskoy H. S. (1990) Teacher Thinking: Personal mechanisms and conceptual apparatus. Moscow: Pedagogy.

${ }^{9}$ Slastenyn V. A. (1976) The formation of the personality of the teacher of the Soviet school in the process of training. Moscow: Prosveshchenye.

${ }^{10}$ Sokolova E. T. (1989) Self-awareness and self-esteem in case of personality anomalies. Moscow: Moscow State University. 
This prompted us to conduct studies on the preparedness of teachers and future teachers to solve educational problems. The group consisted of 150 people (80 graduates of pedagogical specialties, 70 young specialists with work experience up to 5 years). The purpose of this study was the assessment by experts the preparedness of respondents to solve pedagogical problems. The results of the assessment were expressed in the following gradation of the preparedness levels of respondents:

Very low level: the actions of the teacher are not grounded or conscious; pedagogical activity does not meet the requirements of the principles of science and education.

Low level: the actions of the teacher are partially substantiated and partly conscious, significant mistakes are possible; pedagogical activity partially meets the requirements of the principles of education and upbringing.

Middle level: the actions of the teacher as a whole are substantiated and conscious; pedagogical activity as a whole meets the requirements of the principles of education and upbringing; designed activities are completed in a timely manner; there is a considerable degree of independence.

High level: the actions of the teacher are fully justified and conscious; pedagogical activity fully meets the requirements of the principles of education and upbringing; high level of independence; projected activities are completed on time.

The table summarizes the results of expert assessments.

Table 1

Summarized results of expert assessments (in \%)

\begin{tabular}{|c|c|c|c|c|}
\hline \multirow{2}{*}{ Respondents } & \multicolumn{4}{|c|}{ Preparedness levels } \\
\cline { 2 - 5 } & $\begin{array}{c}\text { high } \\
\text { level }\end{array}$ & $\begin{array}{c}\text { medium } \\
\text { level }\end{array}$ & $\begin{array}{c}\text { low } \\
\text { level }\end{array}$ & $\begin{array}{c}\text { very low } \\
\text { level }\end{array}$ \\
\hline \multicolumn{1}{|c|}{ Graduates } & 11 & 27 & 39 & 23 \\
\hline $\begin{array}{l}\text { Young teachers } \\
\text { (with experience } \\
\text { up to 5 years) }\end{array}$ & 19 & 29 & 35 & 17 \\
\hline
\end{tabular}


The results obtained indicate the following trends:

1. There is an increasing number of teachers with a high and medium level of readiness to solve pedagogical tasks. This is a consequence of the adaptation of young teachers to their professional activities, their self-education and self-upbringing.

2 . There is a fairly large proportion of graduates with a low and very low level of preparedness for solving pedagogical problems. It is advisable to emphasize that positive dynamics was diagnosed depending on the length of service, but it is very insignificant and does not satisfy modern requirements.

The analysis of conversations with graduates and young teachers, regarding their use of modern innovative methods in the practical work, concepts of psychology and pedagogy, revealed that real pedagogical activity can be performed at empirical and conscious levels.

The empirical level demonstrates the realization of only the external, substantive side of pedagogical activity, when teachers apply a method of action according to the logic of practical action. However, that logic does not reflect the systemic linkages between the components of the pedagogical process, which is the competence of the theory. Teachers are not able (and do not understand the need) to justify what course of actions and why they were chosen in a particular situation. They just act in a similar way to other teachers.

The conscious level demonstrates the realization that the external objective activity comes out of the previous internal, theoretical work. Thus, the teacher first comprehends the goals and determines the expected results, plans actions, the conditions for their implementation. A. N. Leontyev noted that conscious action, he emphasizes, is a process subordinated to a conscious goal, which leads to a predicted result $\mathrm{t}^{11}$.

Very often there is a discrepancy between the processes of teachers' acquisition of theoretical knowledge and the accumulation of practical experience. These processes seem to coexist in parallel, do not overlap. All this indicates that the theory is not the basis for understanding and choosing the solution of pedagogical problems,

11 Leont'ev A. N. (1975) Activity. Consciousness. Personality. Moscow: Polytyzdat. 
teachers do not use the acquired knowledge to make constructive schemes of problem solving, especially those who have a low or very low level of readiness to find practical solutions.

Interviews with respondents who demonstrated a high and middle level of preparedness to solve pedagogical problems indicate that young professionals (including graduates) are able to use analysis, generalizations, critically reflect on their own experience, observe and use the experience of others. That is, they are in a reflexive position, which has allowed them to succeed.

Respondents who have demonstrated a low and very low level of readiness to solve pedagogical problems are not able to analyze, make generalizations, do not comprehend their own experience, and use the experience of others formally, without understanding, intuitively in their actions. That is, they do not know how to use reflection. This is what led to their result.

Therefore, in order to formulate the ability to solve pedagogical problems, it is necessary to systematically and purposefully develop reflection, reflexive processes. Such organization of these processes will enable the teacher to develop as a professional.

\section{Psychological features of teacher's reflection in the process of developing perceptual skills}

The defining aspects of human existence are subject activity and communication. Of course, there are various interconnections and transitions between them, but this does not exclude their fundamental specificity. The central system-forming attitude that underlies the learning activity and defines its essence is the "teacher-schoolchildren" attitude. The subject of the teacher's activity is the schoolchildren's educational activity. He/she must organize and regulate it in accordance with the tasks of training and their upbringing, subordinated, in turn, to the more general goal of developing the moral and spiritual world of the latter, the formation of the value-semantic sphere of their personality. So, reflexive activity aimed at the schoolchild has its own characteristics. According to the results of various studies, the priority concentration of professional reflective analysis on the schoolchild is not only a consequence of the influence of any situational factors or personal qualities of the teacher, but also 
largely represents the result of the teacher's professional evolution, a reflection of his/her high level of professionalism ${ }^{12}$.

The main guideline of the reflective consciousness of the teacher, that directs and organizes all his/her actions, is the schoolchild. However, the formation of this guideline does not occur immediately and not spontaneously. This process happens with the help of perceptual processes (understanding of the schoolchild, his/her actions), the processes of establishing relationships, the process of partnership communication.

Communicative reflection is close to cooperative one. Close interaction in the communication process acts as a way of actualizing relationships. Psychological dynamics of communication, which allows establishing and maintaining contacts, exchanging information, maintaining interaction and mutual influencing one another, contributes to the realization and formation of a new level of relationships. Relationships are, first and foremost, the object of subject-personal reflection, and they allow us to adjust the content, style, form of communication.

Experimental work on identifying the basic psychological and educational parameters of perceptual activity in pedagogical interaction was carried out with 18 teachers and 57 schoolchildren. The work was aimed at studying the personal psychological properties and capabilities of the teacher, which form the basis of perceptual interaction. The following psychodiagnostic techniques have been applied in the study: The T. Leary methodology for the diagnosis of interpersonal relations, the $M$. Rokich methodology of value orientations, the Philips methodology for diagnosing the level of school anxiety, author's questionnaire. Methodology of statistical data processing have been applied in the analysis of the obtained results.

In educational communication, it is important for the teacher to understand what the schoolchild perceives as important, meaningful. For this purpose, a survey among schoolchildren and teachers was conducted. The schoolchildren were required to rank the communicative characteristics of the teacher for their importance. Teachers should have ranked the communicative characteristics for

${ }^{12}$ Belukhyn D. A. (1994) Teacher: from love to hate ... Moscow. 
schoolchildren. That is, the purpose of the questionnaire was to investigate how teachers understand their schoolchildren.

The following results have been obtained. Teachers believe that the following characteristics are important for schoolchildren: "the ability to express their opinions and their attitude" (I rank), "novelty of information" (II), "the ability to ask questions" (III); "Respect" (IV) and "logic and simplicity of information" (V). Schoolchildren distinguish the following characteristics: "logicality and simplicity of information" (I), "opportunity to ask questions" (II), "opportunity to express their opinions and their attitude" (III), "respect" (IV) and "novelty of information" (V). Thus, we see differences in the answers: teachers choose characteristics that are inherent in the professionalism of communication, and schoolchildren emphasize characteristics that are inherent in the dialogue communication.

A survey of schoolchildren allowed us to highlight the qualities that schoolchildren want to see in their mentors: sociability, a polite attitude to the interlocutor, the ability to hear the opinion of another, a sense of humor, kindness. Among the characteristic reasons that hinder the establishment of trusting relationships with teachers, schoolchildren primarily mention: teacher indifference, neglect, orientation to authoritarianism, lack of understanding of the interests of another, imposing his/her opinion, inability and unwillingness to listen to the interlocutor, complaints and notations, and the like. In fact, we are talking about the subconscious desire of schoolchildren to implement dialogical communication. Interviews with teachers made it possible to identify the qualities that they most often use in communicating with schoolchildren: persuasion, control of their emotions, the use of non-verbal means, and a variety of information. In fact, we are talking about the subconscious orientation of teachers to authoritarian methods of managing schoolchildren.

For a more thorough analysis of communicative aspirations, the Leary Questionnaire was used. The results of the study on average values are presented in Fig. 1. 


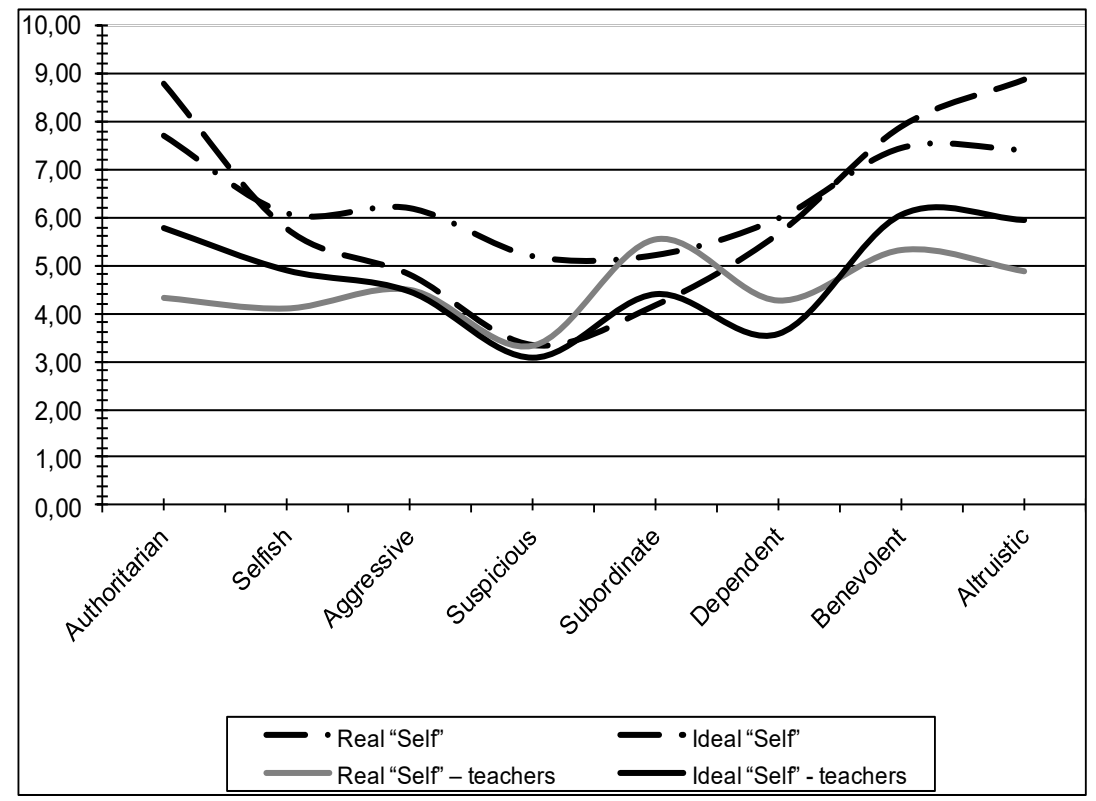

Fig. 1. Results of the study according to the Leary questionnaire

The results obtained allow us to distinguish the following trends:

- both schoolchildren and teachers, in their ideal self, tend to increase authoritarianism. This confirms once again the acknowledged problem of teachers - high authoritarianism, and the desire to increase it ideally is alarming. Schoolchildren, in turn, copy the behavior of the teacher and also tend to increase authoritarianism;

- on the scale of selfishness schoolchildren's real and ideal coincide. It should be emphasized that, ideally, teachers see themselves even more selfish. This is confirmed by the trend of the authoritarianism scale;

- ideally, schoolchildren tend to reduce aggression and suspicion. Teachers do not see significant differences between the real and the ideal state of affairs;

- on the scale of "subordination" and "dependence" we find quite unexpected results. Both groups lack freedom; ideally they see less subordination, both categories are under heavy pressure of social circumstances, they feel uncomfortable; 
- positive trends include the tendency to increase benevolence and altruism in both groups, which indicates the possibility of working with both categories of subjects and the fact that emotional burnout has not yet reached a threatening scale.

The generalized results by the T. Leary's method of own ideas about the real self and ideal self of teachers and schoolchildren are presented in Table 2 .

Table 2

The results of the study by the method of $T$. Leary

\begin{tabular}{|l|c|c|c|c|c|c|c|c|}
\hline \multirow{3}{*}{ Scales } & \multicolumn{3}{|c|}{ The real "Self" } & \multicolumn{4}{c|}{ Ideal "Self" } \\
\cline { 2 - 10 } & $\begin{array}{c}\text { school } \\
\text { children }\end{array}$ & \multicolumn{2}{c|}{ teachers } & \multicolumn{2}{c|}{$\begin{array}{c}\text { school } \\
\text { children }\end{array}$} & \multicolumn{2}{c|}{ teachers } \\
\cline { 2 - 10 } & $M$ & $\sigma$ & $M$ & $\sigma$ & $M$ & $\sigma$ & $M$ & $\sigma$ \\
\hline Authoritarian & 7,68 & 3,07 & 4,33 & 3,20 & 8,77 & 3,46 & 5,78 & 3,59 \\
\hline Selfish & 4,06 & 2,62 & 4,11 & 2,22 & 5,74 & 2,63 & 4,89 & 2,61 \\
\hline Aggressive & 6,17 & 3,08 & 4,50 & 2,55 & 4,79 & 2,55 & 4,44 & 2,75 \\
\hline Suspicious & 5,17 & 2,89 & 3,33 & 2,50 & 3,32 & 2,60 & 3,06 & 2,39 \\
\hline Subordinate & 5,19 & 3,00 & 5,56 & 1,82 & 4,15 & 2,65 & 4,39 & 2,70 \\
\hline Dependent & 5,96 & 2,67 & 4,28 & 2,65 & 5,64 & 3,02 & 3,56 & 2,20 \\
\hline Benevolent & 7,43 & 2,91 & 5,33 & 2,63 & 7,87 & 3,51 & 6,06 & 3,21 \\
\hline Altruistic & 7,38 & 3,35 & 4,79 & 3,45 & 8,85 & 3,75 & 5,94 & 3,78 \\
\hline
\end{tabular}

The findings confirm the crisis of schoolchild-teacher interaction and the inability of existing methods to overcome it: the system of interaction mainly works in a stressful mode for both teachers and schoolchildren, does not suit both parties and requires finding ways to solve the problem.

The peculiarities of anxiety were investigated by the Phillips method. The analysis of the results indicates a significant polarization of the data on the "Overall anxiety at school" scale (standard deviation 4.69). From the additional subscales of the method it is necessary to pay attention to the high value on the scale "Frustration of the need for achievements" (4.11). Thus, we associate the high results on the scale of frustration of the need for achievement with the high values of the reduction of personal achievements among teachers. In other words, this is the spread, translation of the effects of burnout on schoolchildren. 
The results of overall anxiety are also at a high level $(17,23)$, which is an indicator of the problems of pedagogical interaction between teacher and schoolchild. We associate a high level of fears of interaction with such a brightly high value of authoritarianism and independence among students. They are trying to defend themselves from the teacher.

Table 3

The results of the Philips' methodology for diagnosing the level of school anxiety

\begin{tabular}{|c|c|c|c|c|c|c|c|c|c|}
\hline & 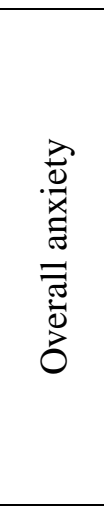 & 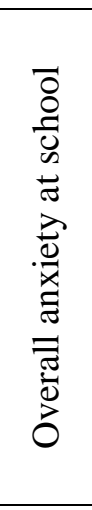 & 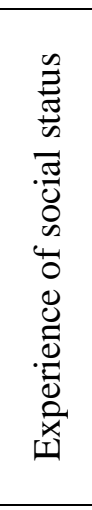 & 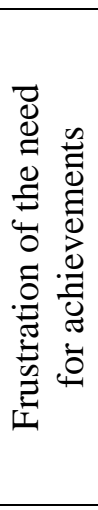 & 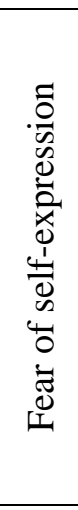 & 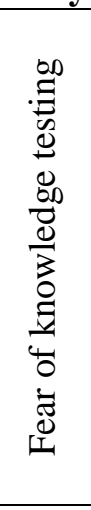 & 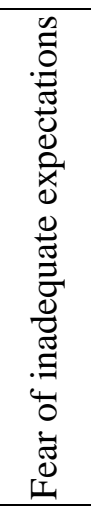 & 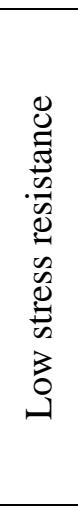 & 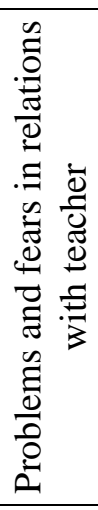 \\
\hline$M$ & 17,23 & 6,60 & 2,81 & 4,11 & 2,23 & 2,49 & 2,26 & 1,28 & 3,11 \\
\hline$\sigma$ & 8,02 & 4,69 & 1,88 & 1,60 & 1,83 & 1,57 & 1,31 & 1,28 & 1,51 \\
\hline
\end{tabular}

Value orientations are general regulators of human behavior and are manifested in absolutely all spheres of human activity, it is virtually impossible to fully characterize any phenomenon of public or individual life without addressing the problem of values and value orientations. Therefore, the next stage of the study was the analysis of value orientations by the Rokich method (see Fig. 2 and Fig. 3).

Assessing the terminal values of schoolchildren and teachers, we can conclude that the schedule is very similar, and, consequently, the structure of values. Only high values on the scale of "life wisdom" among schoolchildren and on the scale of "having friends" among teachers cause confusion. 


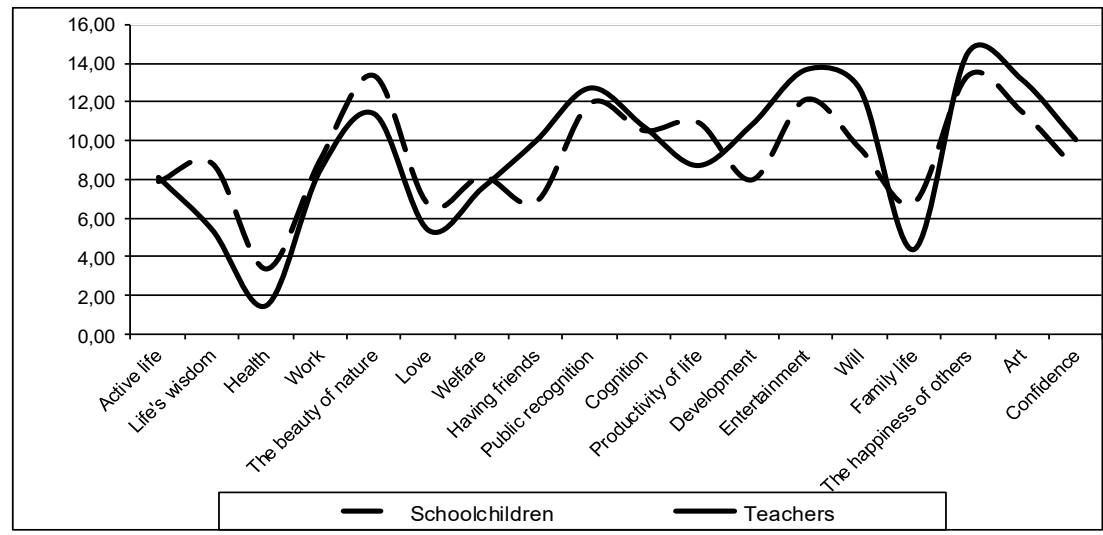

Fig. 2. Terminal values by Rokich method

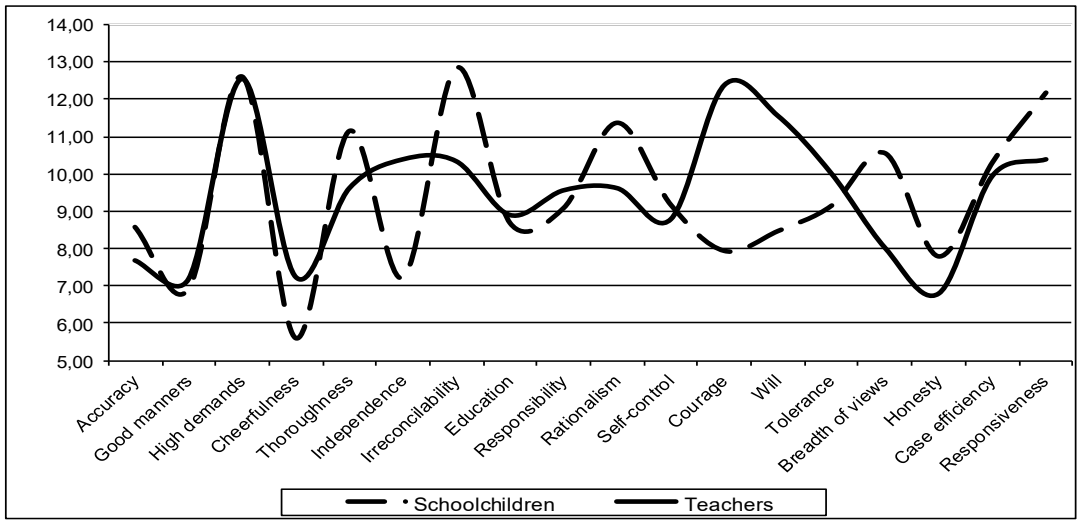

Fig. 3. Instrumental values by the method of Rokich

Instrumental values are much more polar, and the curves of schoolchildren and teachers. The will, courage, self-control are significantly higher among teachers, while "irreconcilability" and "breadth of views" are higher among schoolchildren. Most results are explained by age-related changes, life experiences. At the same time, low indicators of the level of honesty as values among teachers, not too high responsibility, low level of responsiveness, which is a disappointing conclusion on the personal and professional development of the studied teachers, are of concern. 
The next stage of the study is a statistical analysis of the results obtained. Correlation analysis determines the extent of the relationship between different questionnaire scales. The results are noteworthy: overall anxiety (0.731) and overall anxiety at school (0.664), fears of knowledge testing (0.688), inconsistencies (0.435) and relationships with the teacher $(0.428)$ are found to be correlates of stress resistance. In other words, a deep experience of increased anxiety and fears is a means of training stress resistance.

The applied factor analysis made it possible to distinguish the scales with the highest factor loads. The result was a three-factor model that included all the questionnaires. Based on the graph of eigenvalues, a factor matrix has been obtained. In the analysis, the Kettel criterion was used. We note that the factor loads of the extracted factors are high: $20 \%, 18 \%$, and $16 \%$ for the 1st, 2nd, and 3rd factors, respectively, allows us to conclude not only the equivalence of factors, but also the qualitative results of actual factorization.

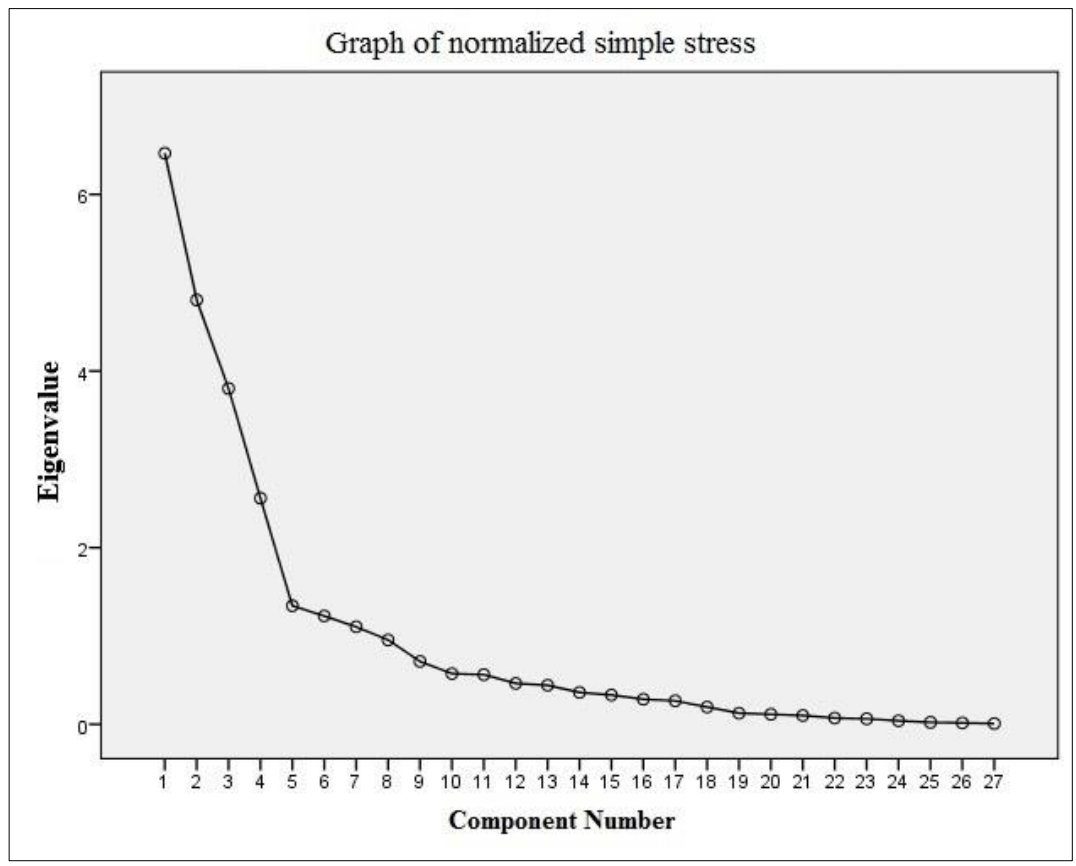

Fig. 4. Graph of the eigenvalues of the obtained factors 
Factor distribution analysis: primary eigenvalues, the sum of the squared factor loads for the extracted factors and the sum of the squared factor loads after rotation is necessary to determine the proportion of variance, "explained" by the extracted factors are presented in Table. 4.

Table 4

The components of the total variance for the 3 factor model

\begin{tabular}{|c|c|c|c|c|c|c|c|c|c|}
\hline \multirow[b]{2}{*}{ 总 } & \multicolumn{3}{|c|}{ Initial eigenvalues } & \multicolumn{3}{|c|}{$\begin{array}{l}\text { The sum of the squared } \\
\text { factor loads for the } \\
\text { extracted factors }\end{array}$} & \multicolumn{3}{|c|}{$\begin{array}{l}\text { Sum of squared factor } \\
\text { loads after rotation }\end{array}$} \\
\hline & 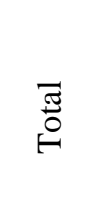 & 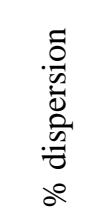 & 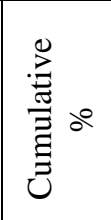 & 胥 & 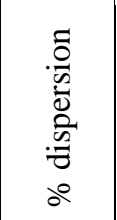 & $\frac{\stackrel{D}{\Xi}}{\stackrel{\Xi}{\Xi}_{\Xi}^{\Xi}}{ }^{\circ}$ & 胥 & 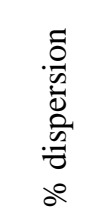 & $\frac{\stackrel{D}{\Xi}}{\stackrel{\Xi}{\Xi}_{\Xi}^{\Xi}}$ \\
\hline 1 & 6,466 & 23,949 & 23,949 & 6,466 & 23,949 & 23,949 & 5,383 & & וער,19ו \\
\hline 2 & 4,805 & 17,795 & 41,744 & 4,805 & 17,795 & 41,744 & 4,877 & 18,064 & 38,000 \\
\hline 3 & 3,802 & 14,081 & 55,825 & 3,802 & 14,081 & 55,825 & 4,421 & 16,373 & 54,374 \\
\hline
\end{tabular}

So, the following distribution of factors has been obtained:

1. "Anxiety and fear" factor (19.94\% of the variance), which included the following indicators: overall anxiety at school, experience of social stress, frustration of need for achievement, fear of selfexpression, fear of knowledge test, fear of non-compliance, resistance to stress, problems and fear of relationships with the teacher. That is, it is an emotional state against which social contacts with peers develop; unfavorable psychological background that does not allow developing one's needs for success; negative emotional experiences of situations, demonstration of oneself and one's capabilities; orientation on the importance of others in evaluating one's results, actions, thoughts; a general negative emotional background of relationships with teachers at school that impairs the schoolchild's ability to learn successfully.

2. Subordination factor ( $18.06 \%$ of variance). The factor included indicators: dependent, benevolent, altruistic, subordinate. That is, it depends on the social environment, on professional activity, on others, 
on circumstances; display of friendliness, kindness, altruism, selflessness and a willingness to obey.

3. The "Dominance" factor (16.37\% of the variance) includes indicators: selfish, aggressive, authoritarian, suspicious. That is, putting one's own needs, desires, manifestations of aggression in communication, interaction and position; acceptance of authoritarianism or expression of authoritarianism, immutability, as well as suspicion, mistrust.

As a result of the analysis it is possible to draw the following conclusion: the basic determinants that determine the object of our study are the factors of dominance, subordination and personal experiences of states of anxiety and fear. This allows us to identify these factors as the main levers of influence for the future correction of teacher-schoolchild communication performance, which in turn will improve schoolchildren's motivation for learning and academic achievement on a global scale, and will be the direction for further research to change the structure of interaction at school in general.

Thus, the value is statistically greater than that of the schoolchildren on all scales that showed statistically significant difference. And if on most scales this is the obvious and expected result, then on the scale "dependent" we expected the opposite. However, the obtained results indicate, in general, greater development of personality traits and qualities among adults on the one hand, but on the other, the presence of occupational deformities among the investigated teachers. In addition, it should be noted that according to the Self - Ideal Scales selfishness, authoritarianism schoolchildren tend to the values of adult teachers and see a high level of selfishness and authoritarianism as the desired ideal; on the other hand, they do not aspire to ideal values on the scale of benevolence and altruism, and do not wish to ideally develop these properties. It is this that explicates, demonstrates an important social problem in society, is an alarming sign of the direction of development of modern youth and sets the task of finding ways to correct these shifts both on a cultural, macro-scale and at the level of individual polydiad teacher-schoolchild interaction.

Empirical study made it possible to single out the psychological properties of the qualities of a teacher's personality through which it is possible to indirectly influence the development of perceptual skills and professional reflection. 


\section{CONCLUSIONS}

Professional reflection (that is, the focus of consciousness on oneself as a specialist, on the content of professional actions, on performing professional tasks) is an important factor of professionalism, competence, professional maturity, as it increases the efficiency of solving a wide range of everyday pedagogical problems.

In this sense, professional reflection is an important mechanism in the process of solving pedagogical problems, since it allows a person to take an external position in relation to himself/herself and his/her actions, which makes their conscious regulation possible. Thanks to reflective learning processes, solving educational problems is more efficient and optimized. The formation of such a skill uses the reflexive mechanism of the transition of activity from the internal form to the external, that is: the deployment of already formed mental actions that are inherent in personal reflection as an ontogenetically earlier variety of reflection. The role of reflection in the process of analyzing the teacher's own constructive and methodical schemes, which he/she uses in the process of solving educational problems, is important. The existence of a direct relationship between the teacher's orientation to independence in the design of educational solutions, the level of formation of his/her professional reflection and the methods of selecting information from various sources has been proved.

Empirical study of the professional development of teachers has been carried out - the ability to solve educational and pedagogical problems. The obtained results indicate the following trends:

- increasing of number of teachers with high and medium level of readiness to solve pedagogical tasks in accordance with their practical experience. Such personalities are able to use analysis, generalizations, critically reflect on their own experience, observe and use the experience of others. That is, they are in a reflexive position, which has allowed them to succeed.

- the presence of a sufficiently large proportion of graduates of pedagogical specialties with low and very low level of readiness to solve pedagogical tasks. They do not know how to analyze, do not generalize, do not comprehend their own experience, and use the experience of others in their actions formally, by analogy. That is, they do not know how to use reflection. 
- there is a discrepancy between the processes of teachers' acquisition of theoretical knowledge and their accumulation of practical experience. These processes coexist as if they were parallel, do not overlap. All this indicates that the theory is not the basis for understanding and choosing the solution of pedagogical problems, teachers do not use the acquired knowledge to make constructive schemes of problem solving, especially those who have a low or very low level of readiness to find practical solutions.

Therefore, for the formation of the ability to solve pedagogical problems, it is necessary to systematically and purposefully develop reflection, reflexive processes. Such an organization of these processes will enable the teacher to develop as a professional.

Communicative reflection is close to cooperative one. Close interaction in the process of communication acts as a way to actualize relationships. It is relations that are, first and foremost, the object of subjective-personal reflection, it is they that allow adjusting the content, style, form of communication.

The following results of the empirical study have been obtained:

- differences in perceptions of factors that are important in educational communication have been diagnosed: teachers choose characteristics that are inherent in professional communication, and schoolchildren emphasize the features that are inherent in dialogical communication;

- the qualities that schoolchildren want to see in their mentors have been distinguished: communicativeness, polite attitude to the interlocutor, ability to hear the opinion of another, sense of humor, kindness;

- systematic psychological features of teachers that interfere with the establishment of perceptual interaction with schoolchildren: the indifference of the teacher, the superficial attitude, the focus on authoritarianism, misunderstanding the interests of others, imposing their thoughts, inability and unwillingness to listen to the interlocutor.

- schoolchildren's and teachers' aspirations in their ideal self to: increase authoritarianism; reduction of subordination; increase in benevolence and altruistic, have been diagnosed;

- a high level of anxiety has been established, which is an indicator of the problems of perceptual pedagogical interaction of teacher-schoolchild; 
- the polarity of indicators of instrumental values hs been revealed: will, courage, self-control are significantly higher among teachers; irreconcilability and breadth of views - among the schoolchildren. Such results are explained by age-related changes, life experiences.

- The teachers' low levels of honesty, responsibility and responsiveness have been identified.

Correlation analysis shows that overall anxiety (0.731) and overall anxiety at school (0.664), fears of knowledge testing (0.688), mismatch $(0.435)$ and relationships with the teacher $(0.428)$ are correlates of stress resistance. In other words, deep feelings of anxiety and fears are a means of stress training.

The applied factor analysis made it possible to distinguish the scales with the highest factor loads, namely, "Anxiety and fears", "Subordination", "Domination". These factors are the main levers of influence for the future correction of the perceptions of teacherschoolchild communication, which in turn will enhance schoolchildren's motivation for learning and academic achievement on a global scale, and will be a driving force for further research on changing interaction structures in modern school interaction.

Thus, the psychological properties of teachers who can optimize communication in training, exchange information, understand the schoolchild, evaluate the effectiveness of their actions, develop perceptivity, maintain interaction and mutual influence on each other, promote the implementation and formation of partnerships in relationships have been highlighted. It is these relationships that are, first of all, the object of subjective-personal reflection, it is they that allow adjusting the content, style, form of communication in training.

\section{SUMMARY}

A necessary condition for pedagogical improvement is professional reflection. The criteria for effective pedagogical activity are: the ability of a teacher to solve pedagogical and educational problems; development of perceptual learning relationships.

The existence of a direct relationship between the teacher's orientation to independence in the design of educational solutions, the level of formation of his/her professional reflection and the methods of selecting information from various sources has been proved. The results of 
empirical study of the process of solving pedagogical problems highlight trends: an increase in the number of teachers with a high and medium level of preparedness for solving pedagogical problems in accordance with the acquisition of experience; the presence of a sufficiently large proportion of graduates of pedagogical specialties with a low and very low level of preparedness for solving pedagogical problems; there is mismatch in the processes of teachers mastering theoretical knowledge and their accumulation of practical experience.

Learning relationships are an object of communicative reflection. The results of empirical study of communication in teaching are as follows: differences in the perception of factors that are important in educational communication have been diagnosed; the qualities that students want to see in their mentors have been highlighted; the psychological qualities of teachers that prevent the establishment of perceptual interaction with students have been systematized; the aspirations of students and teachers has been diagnosed in their ideal Self to: increase authoritarianism; reduction of subordination; increased friendliness; a high level of anxiety has been established, which is an indicator of problems of perceptual pedagogical interaction of teacher-student.

Applied correlation and factor analysis allowed us to highlight the scales that have the greatest factor loads: "Anxiety and fears", "Submission", "Domination". These factors are the basic leverage for the future correction of the perceptivity of communication between teacher and student.

\section{REFERENCES}

1. Rachenko Y.P. (1999) Psychology of pedagogical creativity. Pyatigorsk: Publishing house of PSLU.

2. Klaryn M.V. (1994) Innovative models of teaching in foreign pedagogical searches. Moscow.

3. Zeer E.F. (2003) Psychology of vocational education. Moscow: Publishing House of the Moscow Psychological and Social Institute.

4. Klymov E.A. (1996) Psychology of professional selfdetermination. Rostov-on-Don: Phoenix.

5. Stepanov S.Yu., Polyshchuk O.A. \& Semenov Y.N. (1996) The development of reflective competence of management personnel. Moscow: Progress. 
6. Tkachuk S.I. (2010) Psychological and pedagogical bases of professional readiness of future teachers of labor training to formation of technological culture of students in general educational establishments. Scientific journal of MP Dragomanov National Pedagogical University. Series 13: Challenges for Employment and Training, vol. 6. pp. 200-207.

7. Halkyna N.V. (1990) The psychological mechanism for solving problems of assessment and self-esteem. Psychology of creativity. pp. 149-158.

8. Kulyutkyna Yu.N. \& Sukhobskoy H.S. (1990) Teacher Thinking: Personal mechanisms and conceptual apparatus. Moscow: Pedagogy.

9. Slastenyn V.A. (1976) The formation of the personality of the teacher of the Soviet school in the process of training. Moscow: Prosveshchenye.

10. Sokolova E.T. (1989) Self-awareness and self-esteem in case of personality anomalies. Moscow: Moscow State University.

11. Leont'ev A.N. (1975) Activity. Consciousness. Personality. Moscow: Polytyzdat.

12. Belukhyn D.A. (1994) Teacher: from love to hate ... Moscow.

\section{Information about the author:} Tatiana Scherban

Doctor of Psychology, Professor, Mukachevo State University 26, Uzhgorodska str., Mukachevo, Transcarpathian region, 89600, Ukraine ORCID ID: orcid.org/0000-0002-3702-8029

E-mail: schtata2015@gmail.com 